\title{
Immunohistochemical Cal9-9 in primary colonic polyps and polyps synchronous with colorectal cancer
}

\author{
N H AFDHAL, A LONG, I TOBBIA, A CUllen, AND D P O’DONOGHUE \\ From The Departments of Gastroenterology and Histopathology, St Vincent's Hospital and University College, \\ Dublin, Ireland
}

SUMMARY A prospective study was undertaken to examine the immunohistochemical expression of tumour antigen Cal9-9 in 56 colorectal cancers and 95 colonic adenomas, divided into 65 primary polyps and 30 polyps synchronous with colorectal cancer. Seventy five per cent of tumours were positive for Cal9-9. Antigen was expressed more frequently in advanced Duke's C and D and poorly differentiated colorectal cancer. Overall $51 \%$ of adenomas were positive for Cal9-9. Antigen expression correlated significantly with increasing size $(\mathrm{p}<0.001)$, synchronicity with colorectal cancer $(p<0 \cdot 001)$, severe dysplasia $(p<0.001)$ and villous typing $(p<0.003)$. Discriminate analysis using the first three variables correctly classified $79 \%$ of positive and $89 \%$ of negative Cal9-9 results. The similar frequency of antigen expression seen in colorectal cancers and their synchronous adenoma suggests a field change in the tumour bearing colon. Adenomas positive for Cal9-9 may have a greater malignant potential for carcinomatous change.

Colorectal cancer is one of the commonest fatal malignancies in both men and women in the Western World.' Aetiological factors involved in the pathogenesis of colorectal cancer still remain obscure. Colorectal cancer is, however, one of the few malignancies where a precursor lesion has been identified and most authorities now accept the adenomacarcinoma sequence in the pathogenesis of the majority of large bowel adenocarcinomas. ${ }^{2-6}$ Risk factors for malignant change in adenomata include increasing size, dysplasia, and villous component. ${ }^{2}{ }^{7}$

The advent of monoclonal antibodies has led to the discovery of many new tumour related antigens. One such antibody Cal9-9 has received much attention. ${ }^{\text {. }-15}$ The antigen identified by Cal9-9 is a sialoglycoprotein with a sugar sequence related to sialosyl lacto-N-fucopentaose II. ${ }^{1617}$ Raux et al have demonstrated the antigen in fetal bowel and suggest that it is possibly an oncofetal antigen. ${ }^{18}$ Arends et al have shown by immunohistochemistry the presence of Cal9-9 in normal mucosa of endocervix, gall

Address for correspondence: Dr D P O'Donoghuc. St Vincent`s Hospital. Elm Park. Dublin 4. Eire.

Received for publication 13 August 1986. bladder, and pancreas. ${ }^{19}$ Our previous study showed increasing expression of the antigen in malignant colorectal disease when compared with normal and benign inflammatory colonic lesions and outlined the value of Cal9-9 in examining malignant potential. ${ }^{20}$ Surprisingly, within that selected series of adenomatous polyps there was no correlation between histological type of adenoma and Cal9-9 expression.

Thus, the aims of this prospective study were to further define expression of Cal9-9 by colorectal adenomata and to correlate this expression with other independent determinants of malignant potential in these polyps. Adenomata synchronous with colorectal cancer were compared with primary colorectal polyps to determine the possible effects of colonic environment on antigen expression.

\section{Methods}

PATIENTS

All patients attending St Vincent's Hospital with colorectal adenomata or cancers resected between 1 January and 31 December 1984 were included in the study. Clinical features, site of lesion, and where 
appropriate, modified Duke's staging were recorded for all patients. ${ }^{21}$

\section{HISTOLOGICAL FEATURES \\ Macroscopic}

All resected colorectal cancer specimens were examined and the presence or absence of synchronous polyps recorded. The location, size, and number of these polyps was noted and their distance from the $1^{\circ}$ colorectal cancer measured. Polyps were divided into adjacent - that is, within $5 \mathrm{~cm}$ of colorectal cancer, or distant - greater than $5 \mathrm{~cm}$ from colorectal cancer.

The location, size, and number of $1^{\circ}$ colorectal polyps was recorded either at the time of surgery or of colonoscopic polypectomy.

\section{Microscopic}

All cancers and polyps were orientated, formalin fixed, cut and stained with $\mathrm{H}$ and $\mathrm{E}$ in a routine manner. All $\mathrm{H}$ and $\mathrm{E}$ sections were examined by one pathologist (IT) and polyps were classified as tubular, tubulovillous or villous according to the criteria of Morson. ${ }^{22}$ Epithelial cell dysplasia was defined as mild, moderate or severe as proposed by Konishi and Morson. ${ }^{7}$

\section{CA 19-9 INDIRECT IMMUNOPEROXIDASE STAIN} Duplicate $5 \mu \mathrm{m}$ sections were cut from formalinfixed and paraffin embedded tissue. Sections were deparaffinised in xylene, rehydrated in absolute alcohol and washed in water. Endogenous peroxidase was inhibited by pretreatment with $3 \%$ hydrogen peroxide. After a further wash in water and phosphate buffered saline normal rabbit serum in a dilution of 1:5 was applied to each section for 10 minutes. Mouse IgG monoclonal antibody 19-9 was next reacted with one of the sections for 30 minutes at a concentration of $5 \mu \mathrm{g} / \mathrm{ml}$, the other section being treated with normal swine serum as a negative control. After a further wash in PBS, peroxidase conjugated rabbit antimouse antibody was applied at a dilution of 1:30 for 30 minutes. Each slide was subsequently treated with $0.02 \%$ diaminobenzidine and $10 \%$ hydrogen peroxide in PBS for five minutes. Sections were finally counterstained with haemotoxylin, dehydrated and mounted. The presence of Cal9-9 antigen was confirmed by a brown-black colouration. A colorectal cancer which expressed antigen was used as a positive control.

\section{SCORING OF SLIDES}

Cal9-9 incubated slides were compared with control slides independently (NA, IT) and a $98 \%$ agreement was achieved. No visible staining was grade $\mathrm{O}$ and $\mathrm{a}$ weak stain of less than $5 \%$ of the slide, localised to the periphery was grade 1 . Both these grades were considered negative. A focal intense stain of between $5-70 \%$ of the section was grade 2 and a diffuse colouration was grade 3 . Grades 2 and 3 were positive.

STATISTICAL ANALYSIS

Analysis of categorical variables was done using standard $\chi^{2}$ tests, with continuity correction where appropriate. Correlations were performed using Kendall's Tau, a rank-order correlation coefficient, particularly suited to ordinal variables having small numbers of categories. Because of the intercorrelation of the independent variables, a discriminant function analysis was carried out to select the optimum subset to predict Cal9-9 positivity.

The method used was stepwise, in which variables were added one at a time to the discriminant function. When no variable added to the function's power to discriminate between Cal9-9 positive and negative patients, the selection process was halted.

\section{Results}

\section{COLORECTAL CANCER}

Fifty six patients presented during the 12 month period. Details and histological findings are shown in Table 1 . Forty two of 56 colorectal cancers (75\%) examined were positive for Cal9-9 and this antigen expression was more frequent in advanced Duke's C and $\mathrm{D}$ and poorly differentiated tumours.

Cal9-9 was focally positive (Grade 2) in 21 cases and diffusely positive (Grade 3 ) in 21 cases. Antigen localisation was maximal in the apical luminal surface

Table 1 Clinical features and Cal9-9 expression in 56 patients with colorectal cancer

\begin{tabular}{lc}
\hline Age & \\
Range & $31-83$ \\
Mean & $64 \cdot 9$ \\
Sex & \\
M : F & $28: 28$ \\
Duke's staging & \\
A & $3(2)$ \\
B & $26(17)$ \\
C & $15(14)$ \\
D & $12(9)$ \\
Differentiation & \\
Well & $6(3)$ \\
Moderate & $42(32)$ \\
Poor & $8(7)$ \\
Site & $15(11)$ \\
Rectum & $27(18)$ \\
Left colon & $14(13)$ \\
Right colon & $42(75 \%)$ \\
Total number positive for Cal9-9 & \\
\hline
\end{tabular}

( ) =Number positive for Cal9-9. 


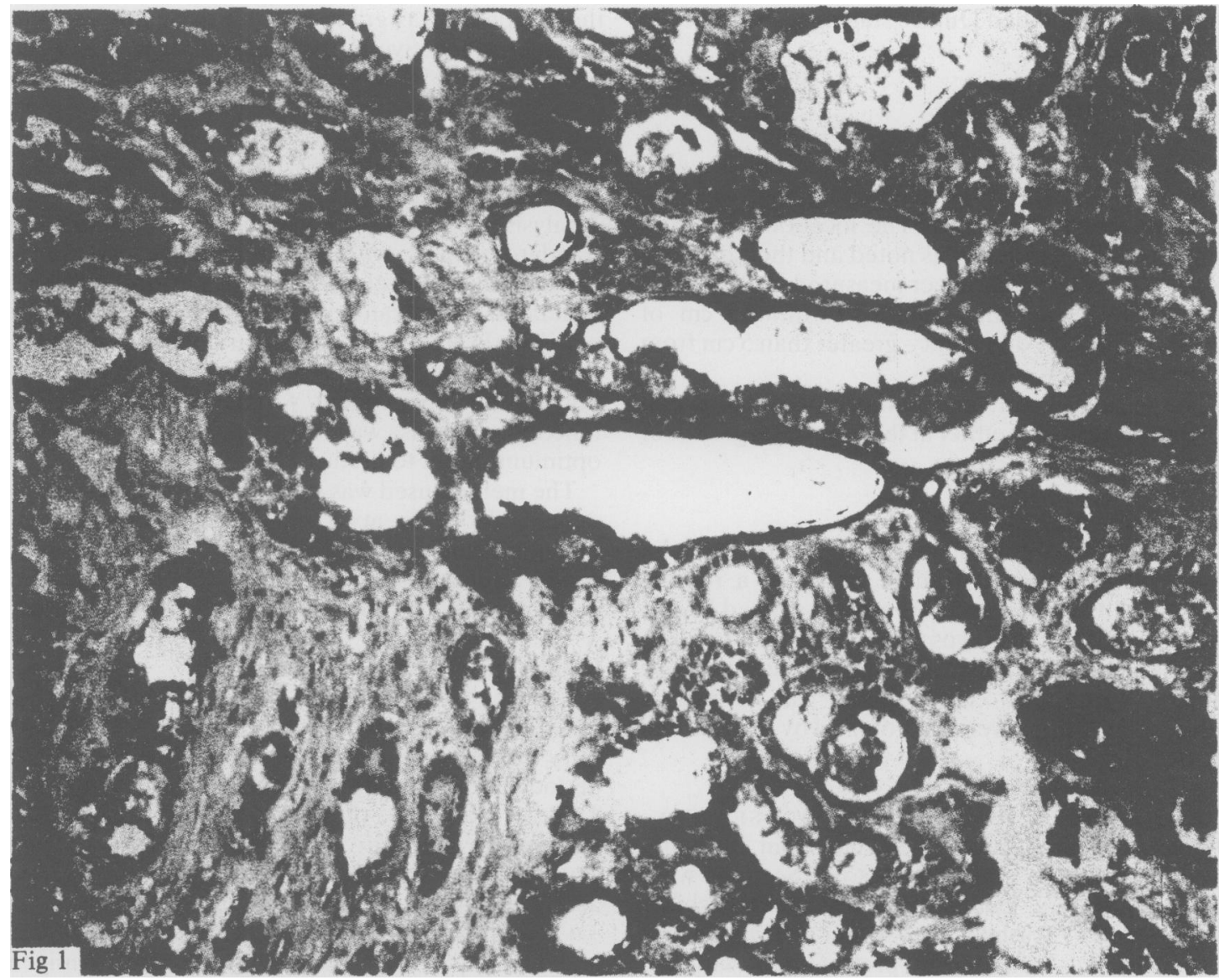

Fig. 1 Moderately differentiated adenocarcinoma showing Cal9-9 localisation diffusely in the apical cells and glandular secretion.

of epithelial cells and in the intraglandular secretions (Fig. 1). Strong cytoplasmic staining was also seen in poorly differentiated colorectal cancers. Histologically normal, so called 'transitional' mucosa adjacent to colorectal cancer was focally positive in 12 of 42 cases.

\section{Adenomatous polyps}

Sixteen of the patients with colorectal cancer had 30 synchronous polyps while a further 36 patients presented with a total of $651^{\circ}$ adenomata over the 12 months. Patient details and histology of polyps are shown in Table 2. Eighty per cent of synchronous polyps expressed Cal9-9 compared with only $37 \%$ of primary polyps $\left(\chi^{2}=13 \cdot 56, \mathrm{p}<0 \cdot(001)\right.$. Cal9-9 positivity correlated strongly with synchronicity of polyps ( Tau $=0.4005, \mathrm{p}<0 \cdot(001)$.

Overall 48 of 95 polyps $(51 \%)$ expressed the antigen. The expression was focal and less intense than in colorectal cancer and only one $4 \mathrm{~cm}$ dysplastic tubulovillous adenoma was Grade 3. Localisation was in the surface epithelium and varied from one high power field to another within the same polyp (Figs 2 and 3 ).

Four patients with a colorectal cancer negative for Cal9-9 had coexistant synchronous polyps that were positive for the antigen. The clinical features of these four cases are outlined in Table 3. Multiple polyps (two to 10) were present in 18 patients. Antigen expression was not uniform in these patients but was generally seen in the larger, dysplastic polyps.

\section{HISTOLOGICAL TYPING}

Tubular adenomas accounted for $65 \%$ of the series with the remainder having variable villous component (Table 4). Cal9-9 was expressed in $40 \%$ of tubular polyps and $70 \%$ of adenomas with villous component $\left(\chi^{2}=6 \cdot 305, p<0 \cdot 01\right)$. Correlation between Cal9-9 expression and villous component was strong $(\mathrm{Tau}=0 \cdot 279, \mathrm{p}<0 \cdot 003)$. 
Table 2 Clinical details and Cal9-9 expression in patients with synchronous and primary adenomata

\begin{tabular}{|c|c|c|c|}
\hline & & $\begin{array}{l}\text { Polyp synchronous } \\
\text { with } C R C(n=30)\end{array}$ & $\begin{array}{l}\text { Primary adenomata } \\
(n=65)\end{array}$ \\
\hline \multicolumn{2}{|c|}{ Paticnts (n) } & 16 & 36 \\
\hline \multirow[t]{2}{*}{ Age (yr): } & Range & $31-80$ & $42-82$ \\
\hline & Mcan & $63 \cdot 9$ & $65 \cdot 1$ \\
\hline Sex: & $\mathrm{M}: \mathrm{F}$ & $11: 5$ & $18: 18$ \\
\hline \multirow{2}{*}{ Site: } & Left & 22 & 65 \\
\hline & Right & 8 & 0 \\
\hline \multicolumn{2}{|l|}{ Tubular } & $23(17)$ & $39(8)$ \\
\hline \multicolumn{2}{|c|}{ Tubulovillous } & $6(6)$ & $22(12)$ \\
\hline \multicolumn{2}{|c|}{ Villous } & $1(1)$ & $4(4)$ \\
\hline \multicolumn{2}{|c|}{ Cal9-9 Positive (\%) } & $24^{*}(80)$ & $24(37 \%)$ \\
\hline
\end{tabular}

${ }^{*} \chi^{2}=13 \cdot 56, p<0 \cdot(0) 1 ;()=$ Number positive for Cal9-9, CRC $=$ colorectal cancer.

DYS PLASIA (see Table 4)

Twenty of 21 severely dysplastic polyps were positive for Cal9-9 when compared with 28 of 74 mild or moderately dysplastic polyps $\left(\chi^{2}=23 \cdot 70, \mathrm{p}<0 \cdot 001\right)$. The correlation between increasing degrees of dysplasia and Cal9-9 expression was significant. $(\mathrm{Tau}=0 \cdot 438, \mathrm{p}<0 \cdot 001)$.
SIZE

Polyp size varied from 0.3 to $4.5 \mathrm{~cm}$ (Table 5). Mean polyp size was $1.28+/-0.96 \mathrm{~cm}$ and this was similar for both primary and synchronous polyps. There was a very strong correlation for increasing polyp size and Cal9-9 expression which was irrespective of whether polyps were $1^{\circ}$ or synchronous $(\mathrm{Tau}=0.475$, $\mathrm{p}<0 \cdot 001)$.

SITE

Eighty seven polyps were located in the left colon and 40 were positive for Cal9-9. The remaining eight caecal and ascending colon adenomas all expressed the antigen. In the synchronous group, 20 polyps were adjacent to their parent colorectal cancer and 10 distant. Seventeen of the 20 adjacent polyps and seven of 10 distant group were positive for Cal9-9.

DISCRIMINATE ANALYSIS

The discriminate function selected polyps synchronous with colorectal cancer, size and dysplasia as independently differentiating between Cal9-9 positive and negative patients. Size accounted for $26 \%$ of variance between Cal9-9 results, the addition of

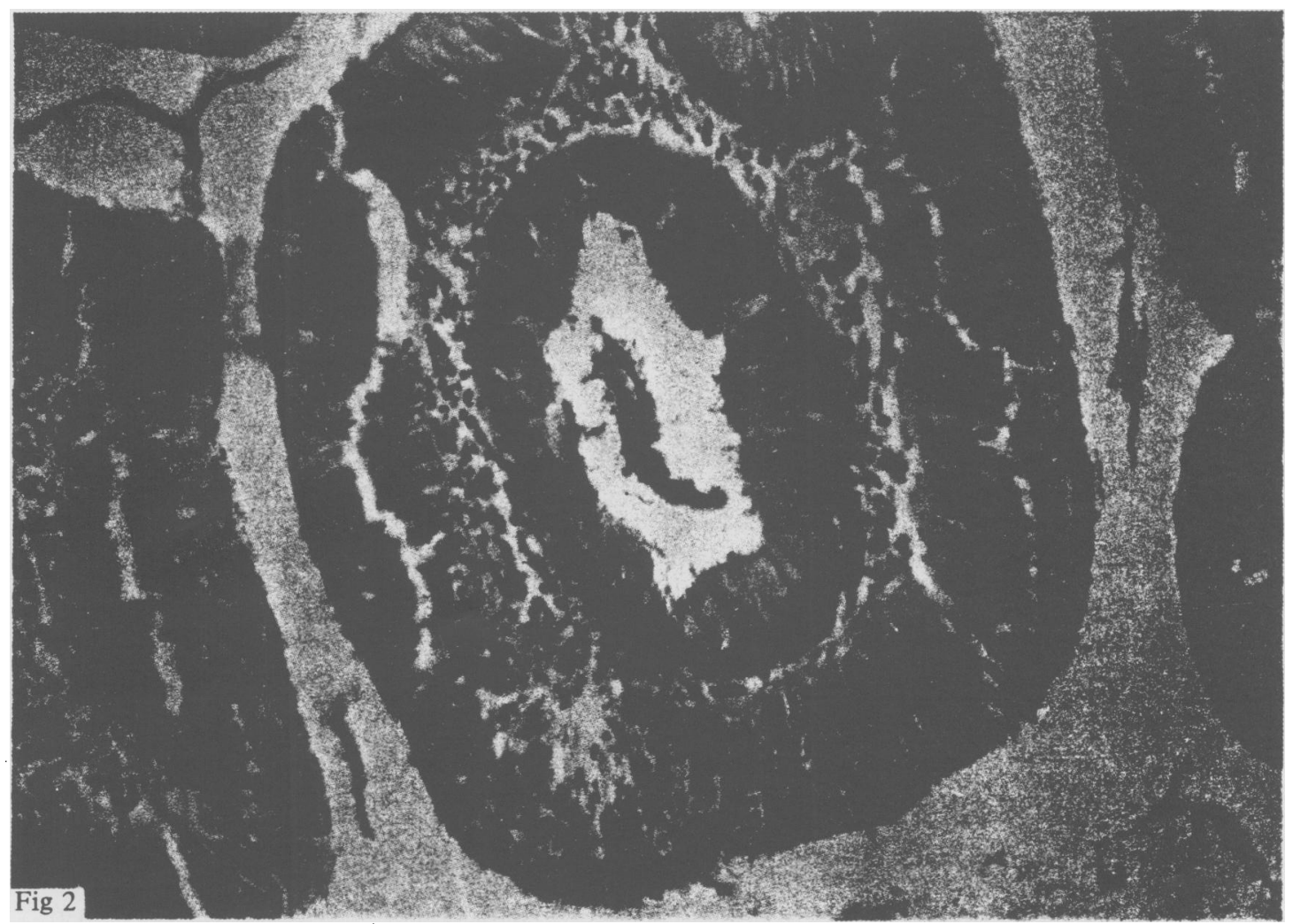

Fig. 2 Tubular adenoma, severely dysplastic demonstrating surface localisation of antigen. 


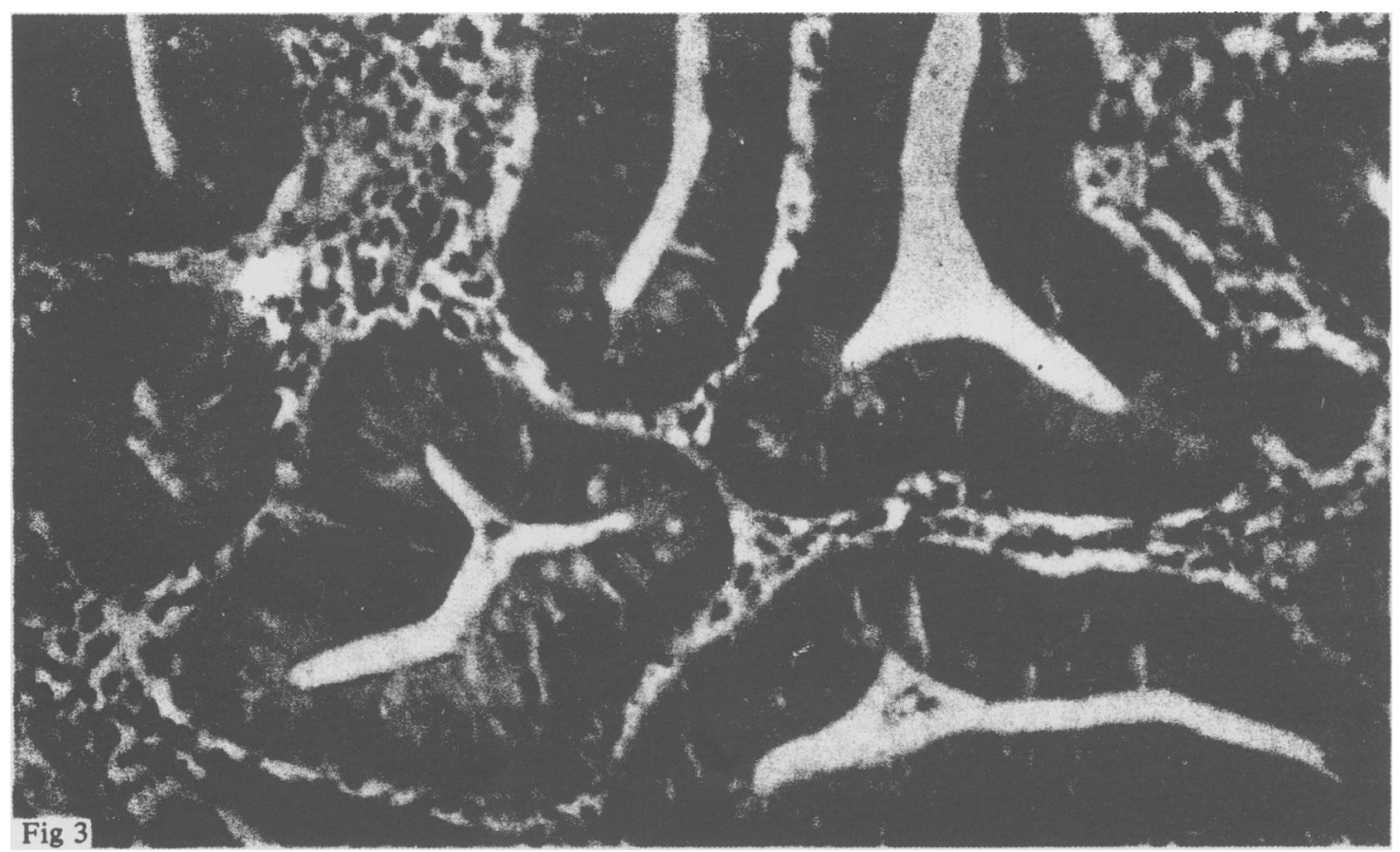

Fig. 3 Tubular adenoma showing focal grade 2 secretion of antigen maximal in areas of dysplasia.

polyp synchronicity increased the percentage of explained variance to $42 \%$ and the third factor, dysplasia increased this to $49 \%$ of Cal9-9 variation. The canonical correlation between the three factors and test result was $0 \cdot 72$. Overall, the three variables correctly classified $79 \%$ of positive and $89 \%$ of negative Cal9-9 results.

\section{Discussion}

The histological expression of the monoclonal antibody Cal9-9 in $60-75 \%$ of patients with colorectal cancer and its relative absence from normal colonic tissue ${ }^{211}$ ' marks it as a useful tool in the evaluation of putative premalignant states, such as the dysplasia seen in inflammatory bowel disease or, as in this study, the adenomatous polyp.

Overall $51 \%$ of polyps examined in this prospective manner displayed the antigen. Interestingly Cal9-9 correlated well with the accepted histological risk factors of size, severe dysplasia and villous component."

Dysplasia and villous component of polyps have correlated well with other proposed markers of malignancy such as CEA and the lectin, peanut agglutinin. ${ }^{-3}$ The loss of villous component with discriminant analysis in our study, is probably accounted for by the fact that these polyps tended to be larger.

Division of our polyps into synchronous and primary showed a marked difference between the

Table 3 Clinical features of four patients with colorectal cancer negative for Cal9-9 but with positive synchronous adenomata

\begin{tabular}{|c|c|c|c|c|c|c|}
\hline \multirow[b]{2}{*}{ C'ase } & \multicolumn{3}{|c|}{ Carcinoma-negative for Cal9-9 } & \multicolumn{3}{|c|}{ Synchronous adenoma-positive for Cal9-9 } \\
\hline & Site & Duke's stage & Differentiation & Histological type & Dysplasia & Size $(\mathrm{cm})$ \\
\hline 1 & Rectal & D & Undifferentiated & Tubular & Moderate & $1 \cdot()$ \\
\hline \multirow[t]{2}{*}{2} & Sigmoid & C & Moderate & (1) Tubulovillous & Severe & $1 \cdot 5$ \\
\hline & & & & (2) Tubulovillous & Mild & $3 \cdot()$ \\
\hline 3 & Sigmoid & B & Moderate & Tubular & Severe & $1 \cdot()$ \\
\hline 4 & Sigmoid & $\mathrm{B}$ & Moderate & Tubulovillous & Severe & $4 \cdot()$ \\
\hline
\end{tabular}


Table 4 Comparison of Cal9-9 antigen expression with histological subtype and dysplasia in 95 colorectal adenomata

\begin{tabular}{lcll}
\hline $\begin{array}{l}\text { Histological } \\
\text { type }\end{array}$ & $n$ & $\begin{array}{l}\text { Cal9-9 positive } \\
(\%)\end{array}$ & $\begin{array}{l}\text { Cal9-9 negative } \\
(\%)\end{array}$ \\
\hline $\begin{array}{l}\text { Tubular } \\
\text { Tubulovillous }\end{array}$ & 62 & $25(40)$ & $37(60)$ \\
Villous & 5 & $18(65)$ & $10(35)$ \\
Dysplasia & & $5(100)$ & 0 \\
$\quad$ Mild & 40 & $12(30)$ & $28(70)$ \\
Moderate & 34 & $16(47)$ & $18(53)$ \\
Severe & $21 \dagger$ & $20(95)$ & $1(5)$ \\
\hline
\end{tabular}

${ }^{*} \chi^{2}=6 \cdot 305, \mathrm{p}<0 \cdot\left(01 ;+\chi^{2}=23 \cdot 70, \mathrm{p}<0 \cdot(0) 1\right.$.

Table 5 Relationship of size to Cal9-9 expression in synchronous and primary adenoma

\begin{tabular}{lll}
\hline $\begin{array}{l}\text { Diameter } \\
(\mathrm{cm})\end{array}$ & $\begin{array}{l}\text { Synchronous polyps } \\
(n=30)\end{array}$ & $\begin{array}{l}\text { Primary polyps } \\
(n=65)\end{array}$ \\
\hline Mean $\pm \mathrm{SD}$ & $1 \cdot 29 \pm 0 \cdot 89$ & $1 \cdot 28 \pm 1 \cdot 0$ \\
$<1 \mathrm{~cm}$ & $10(7)$ & $28(3)$ \\
$1-2 \mathrm{~cm}$ & $15(12)$ & $30(14)$ \\
$>2 \mathrm{~cm}^{*}$ & $5(5)$ & $7(7)$ \\
\hline
\end{tabular}

$(\quad)=$ number positive for Cal9-9: ${ }^{*} \tau=() \cdot 475, p<0 \cdot()() 1$

two groups. This difference in Cal9-9 is not explained by clinical features since size, dysplasia and histological typing was similar in both groups. A spillover effect from the parent colorectal cancer is also unlikely, as both adjacent and distant polyps expressed Cal9-9. The independence of the synchronous polyp from the parent colorectal cancer is further highlighted by the presence of positive polyps in four patients with negative parent colorectal cancers.

The almost equal incidence of antigen expression in colorectal cancer and synchronous polyps suggests a possible field change in the tumour bearing colon. As only $28 \%$ of colorectal cancer had antigen in the 'transitional' mucosa, perhaps a certain mass of proliferating cells must be produced before Cal9-9 is expressed in sufficient quantity to be detected by an immunohistochemical technique.

The presence of Cal9-9 in the 'transitional' mucosa and in a minority of the smaller, mildly dysplastic polyps is of particular interest. This would suggest that although structure and function of cells are closely related that functional changes, such as in mucin production, may precede morphological changes. Screening for changes in sialoglycoprotein secretion may be of value in predicting patients at high risk for colorectal cancer.

The failure of $25 \%$ of the colorectal cancer in this series to express Cal9-9 suggests that some colorectal cancer arise without development of this sialoglycoprotein or, alternatively, lose the ability to do so. The greater frequency of antigen expression in advanced Duke's stage and poorly differentiated tumours would favour the former.

Despite these problems it would appear reasonable to conclude from this work that colorectal cancer may arise from any adenomatous polyp, with size and dysplasia being the important factors, and that changes in Cal9-9 expression may precede these factors. Polyps found in the colon of patients with colorectal cancer would appear to have a greater malignant potential than otherwise identical polyps found by chance.

This study was supported by grants from St Luke's Hospital Research Fund and the Medical Research Council of Ireland. Presented in part to the British Society of Gastroenterology, April, 1985. We would like to thank Centocor, Pa. for generous supply of Cal9-9 antibody, Miss Joyce Foley for her help with the manuscript and Mr Ronan Conroy, Department of Preventative Medicine, for the statistical analysis.

\section{References}

1 Harkin K, MacMahon B, Doyle JS, Kinsella IA. Mortality analysis of colorectal carcinoma in Ireland; time trends and an international comparison. Ir J Med Sci 1985; 154: 343-7.

2 Muto T, Bussey HJR, Morson BC. The evolution of cancer of the colon and rectum. Cancer 1975; 36: 2251-70.

3 Enterline HT, Arvan DA. Chromosome constitution of adenoma and adenocarcinoma of the colon. Cancer 1967; 20: 1746-59.

4 Grinnell RS, Lane N. Benign and malignant adenomatous polyps and papillary adenomas of the colon and rectum. An analysis of 1856 tumours in 1335 patients. Surgery 1958; 106: 519-38.

5 Lane $\mathrm{N}$. The precursor tissue of ordinary large bowel cancer. Cancer Res 1976; 36: 2669-72.

6 Hill MJ, Morson BC, Bussey HJR. Aetiology of adenoma-carcinoma sequence in large bowel. Lancet 1978; 1: 245-7.

7 Konishi F, Morson BC. Pathology of colorectal adenomas: a colonoscopic survey. J Clin Pathol 1982; 35: $830-41$.

8 Koprowski H, Herlyn M, Steplewski Z, Sears HF. Specific antigen in serum of patients with colon carcinoma. Science 1981; 212: 53-5.

9 Herlyn M, Steplewski Z, Herlyn D, Koprowski H. Colorectal carcinoma-specific antigen: Detection by means of monoclonal antibodies. Proc Natl Acad Sci USA 1979; 76: 1438-42.

10 Steplewski Z, Chang TH, Herlyn M, Koprowski H. Release of monoclonal antibody-defined antigens by human colorectal carcinoma and melanoma cells. Cancer Res 1981; 41: 2723-7. 
11 Herlyn M, Sears HF, Steplewski Z, Koprowski H. Monoclonal antibody detection of a circulating tumourassociated antigen. Presence of antigen in sera of patients with colorectal, gastric and pancreatic carcinoma. J Clin Immunol 1982; 2: 135-40.

12 Atkinson B, Ernst C, Herlyn M et al. Gastrointestinal cancer-associated antigen in immunoperoxidase assay. Cancer Res 1982; 42: 4280-3.

13 Arends JW, Wiggers T, Schutte B et al. Monoclonal antibody (1116 NS 19-9) defined monosialoganlioside (GICA) in colorectal carcinoma in relation to stage, histopathology and DNA flow cytometry. Int J Cancer 1983; 32: 289-93.

14 Kuusela P, Jalanko H, Roberts $\mathrm{P}$ et al. Comparison of Cal9-9 and carcinomebryonic antigen (CEA) levels in the serum of patients with colorectal disease. $\mathrm{Br} J$ Cancer 1984; 49: 135-9.

15 Jalanko H, Kuusela P, Roberts $P$ et al. Comparison of a new tumour marker, Cal9-9, with fetoprotein and carcinoembryonic antigen in patients with upper gastrointestinal diseases. J Clin Pathol 1984; 27: 218-22.

16 Magnani JL, Brockhaus M, Smith DF et al. A monosialoganglioside is a monoclonal antibody defined antigen of colon carcinoma. Science 1981 ; 212: 55-6.

17 Hanisch F, Uhlenbruck G, Dienst C. Structure of tumour-associated carbohydrate antigen Cal9-9 on human seminal plasma glycoproteins from healthy donors. Eur J Biochem 1984; 144: 467-74.

18 Raux H, Labbe F, Fondaneche MC, Koprowski H, Burtin P. A study of gastrointestinal cancer-associated antigen (GICA) in human fetal organs. Int $J$ Cancer 1983; 32: 315-9.

19 Arends JW, Verstijnen K, Bosman FT, Hilgers J, Steplewski Z. The distribution of 1116 NS 19-9 monoclonal antibody defined monosialoganglioside in normal and cancerous human tissues. Hybridoma 1983; 2: 81-91.

20 Long A, Tobin B, O’Donoghue DP. Ca 19-9 antibody in colorectal carcinoma and colonic adenomata. Ir J Med Sci 1985; 154: 46.

21 Turnbull RB, Kyle K, Watson FR, Spratt J. Cancer of the colon: influence of the no touch isolation technique on survival rates. Ann Surg 1967; 168: 420-7.

22 Morson BC, Sobin LH, eds. Histological typing of intestinal tumours. In: International histological classification of tumours. Vol. 15. Geneva, WHO: 1976

23 Isaacson P, LeVann HP. The demonstration of carcinoembryonic antigen in colorectal carcinoma and colonic polyps using an immunoperoxidase technique. Cancer 1976; 38: 1348-56.

24 Boland RC, Montgomery CK, Kim YS. A cancerassociated mucin alteration in benign colonic polyps. Gastroenterology 1982; 82: 664-72. 
Gut, 1987, 28, 1049-1055

Reprinted article*

\title{
Immunohistochemical Cal9-9 in primary colonic polyps and polyps synchronous with colorectal cancer
}

\author{
N H AFDhAl, A LONG, I TOBBIA, A Cullen, AND D P O’DOnoghuE \\ From The Departments of Gastroenterology and Histopathology, St Vincent's Hospital and University College, \\ Dublin, Ireland
}

SUMMARY A prospective study was undertaken to examine the immunohistochemical expression of tumour antigen Cal9-9 in 56 colorectal cancers and 95 colonic adenomas, divided into 65 primary polyps and 30 polyps synchronous with colorectal cancer. Seventy five per cent of tumours were positive for Cal9-9. Antigen was expressed more frequently in advanced Duke's C and D and poorly differentiated colorectal cancer. Overall $51 \%$ of adenomas were positive for Cal9-9. Antigen expression correlated significantly with increasing size $(p<0.001)$, synchronicity with colorectal cancer $(p<0.001)$, severe dysplasia $(p<0.001)$ and villous typing $(p<0.003)$. Discriminate analysis using the first three variables correctly classified $79 \%$ of positive and $89 \%$ of negative Cal9-9 results. The similar frequency of antigen expression seen in colorectal cancers and their synchronous adenoma suggests a field change in the tumour bearing colon. Adenomas positive for Cal9-9 may have a greater malignant potential for carcinomatous change.

Colorectal cancer is one of the commonest fatal malignancies in both men and women in the Western World.' Aetiological factors involved in the pathogenesis of colorectal cancer still remain obscure. Colorectal cancer is, however, one of the few malignancies where a precursor lesion has been identified and most authorities now accept the adenomacarcinoma sequence in the pathogenesis of the majority of large bowel adenocarcinomas. ${ }^{2-6}$ Risk factors for malignant change in adenomata include increasing size, dysplasia, and villous component. ${ }^{2}{ }^{7}$

The advent of monoclonal antibodies has led to the discovery of many new tumour related antigens. One such antibody Cal9-9 has received much attention. ${ }^{*-15}$ The antigen identified by Cal9-9 is a sialoglycoprotein with a sugar sequence related to sialosyl lacto-N-fucopentaose II. ${ }^{16}{ }^{17}$ Raux et al have demonstrated the antigen in fetal bowel and suggest that it is possibly an oncofetal antigen. ${ }^{18}$ Arends et al

Address for correspondence: Dr D P O'Donoghue, St Vincent`s Hospital. Elm Park, Dublin 4, Eire.

Received for publication 13 August 1986

*This article is reprinted from our May issue because the Figures should have appeared in colour but owing to technical difficulties they appeared in monochrome. We apologise to the authors and readers for this. For reference purposes the May reference (Git 1987; 28: $594-6(K))$ should apply. have shown by immunohistochemistry the presence of Cal9-9 in normal mucosa of endocervix, gall bladder, and pancreas. ${ }^{19}$ Our previous study showed increasing expression of the antigen in malignant colorectal disease when compared with normal and benign inflammatory colonic lesions and outlined the value of Cal9-9 in examining malignant potential..$^{20}$ Surprisingly, within that selected series of adenomatous polyps there was no correlation between histological type of adenoma and Cal9-9 expression.

Thus, the aims of this prospective study were to further define expression of Cal9-9 by colorectal adenomata and to correlate this expression with other independent determinants of malignant potential in these polyps. Adenomata synchronous with colorectal cancer were compared with primary colorectal polyps to determine the possible effects of colonic environment on antigen expression.

\section{Methods}

\section{PATIENTS}

All patients attending St Vincent's Hospital with colorectal adenomata or cancers resected between 1 January and 31 December 1984 were included in the study. Clinical features, site of lesion, and where 
appropriate, modified Duke's staging were recorded for all patients. ${ }^{21}$

\section{HISTOLOGICAL FEATURES}

Macroscopic

All resected colorectal cancer specimens were examined and the presence or absence of synchronous polyps recorded. The location, size, and number of these polyps was noted and their distance from the $1^{\circ}$ colorectal cancer measured. Polyps were divided into adjacent - that is, within $5 \mathrm{~cm}$ of colorectal cancer, or distant - greater than $5 \mathrm{~cm}$ from colorectal cancer.

The location, size, and number of $1^{\circ}$ colorectal polyps was recorded either at the time of surgery or of colonoscopic polypectomy.

\section{Microscopic}

All cancers and polyps were orientated, formalin fixed, cut and stained with $\mathrm{H}$ and $\mathrm{E}$ in a routine manner. All $\mathrm{H}$ and $\mathrm{E}$ sections were examined by one pathologist (IT) and polyps were classified as tubular, tubulovillous or villous according to the criteria of Morson. ${ }^{22}$ Epithelial cell dysplasia was defined as mild, moderate or severe as proposed by Konishi and Morson. ${ }^{7}$

\section{CA 19-9 INDIRECT IMMUNOPEROXIDASE STAIN} Duplicate $5 \mu \mathrm{m}$ sections were cut from formalinfixed and paraffin embedded tissue. Sections were deparaffinised in xylene, rehydrated in absolute alcohol and washed in water. Endogenous peroxidase was inhibited by pretreatment with $3 \%$ hydrogen peroxide. After a further wash in water and phosphate buffered saline normal rabbit serum in a dilution of 1:5 was applied to each section for 10 minutes. Mouse IgG monoclonal antibody 19-9 was next reacted with one of the sections for 30 minutes at a concentration of $5 \mu \mathrm{g} / \mathrm{ml}$, the other section being treated with normal swine serum as a negative control. After a further wash in PBS, peroxidase conjugated rabbit antimouse antibody was applied at a dilution of $1: 30$ for 30 minutes. Each slide was subsequently treated with $0.02 \%$ diaminobenzidine and $10 \%$ hydrogen peroxide in PBS for five minutes. Sections were finally counterstained with haemotoxylin, dehydrated and mounted. The presence of Cal9-9 antigen was confirmed by a brown-black colouration. A colorectal cancer which expressed antigen was used as a positive control.

\section{SCORING OF SLIDES}

Cal9-9 incubated slides were compared with control slides independently (NA, IT) and a $98 \%$ agreement was achieved. No visible staining was grade $\mathrm{O}$ and a weak stain of less than $5 \%$ of the slide, localised to the periphery was grade 1 . Both these grades were considered negative. A focal intense stain of between $5-70 \%$ of the section was grade 2 and a diffuse colouration was grade 3 . Grades 2 and 3 were positive.

\section{STATISTICAL ANALYSIS}

Analysis of categorical variables was done using standard $\chi^{2}$ tests, with continuity correction where appropriate. Correlations were performed using Kendall's Tau, a rank-order correlation coefficient, particularly suited to ordinal variables having small numbers of categories. Because of the intercorrelation of the independent variables, a discriminant function analysis was carried out to select the optimum subset to predict Cal9-9 positivity.

The method used was stepwise, in which variables were added one at a time to the discriminant function. When no variable added to the function's power to discriminate between Cal9-9 positive and negative patients, the selection process was halted.

\section{Results}

COLORECTAL CANCER

Fifty six patients presented during the 12 month period. Details and histological findings are shown in Table 1 . Forty two of 56 colorectal cancers $(75 \%)$ examined were positive for Cal9-9 and this antigen expression was more frequent in advanced Duke's C and $\mathrm{D}$ and poorly differentiated tumours.

Cal9-9 was focally positive (Grade 2) in 21 cases and diffusely positive (Grade 3 ) in 21 cases. Antigen localisation was maximal in the apical luminal surface

Table 1 Clinical features and Cal9-9 expression in 56 patients with colorectal cancer

\begin{tabular}{lc}
\hline Age & \\
Range & $31-83$ \\
Mean & $64 \cdot 9$ \\
Sex & \\
M : F & $28: 28$ \\
Duke's staging & \\
A & $3(2)$ \\
B & $26(17)$ \\
C & $15(14)$ \\
D & $12(9)$ \\
Differentiation & \\
Well & $6(3)$ \\
Moderate & $42(32)$ \\
Poor & $8(7)$ \\
Site & $15(11)$ \\
Rectum & $27(18)$ \\
Left colon & $14(13)$ \\
Right colon & $42(75 \%)$ \\
Total number positive for Cal9-9 & \\
\hline
\end{tabular}

( ) = Number positive for Cal9-9. 


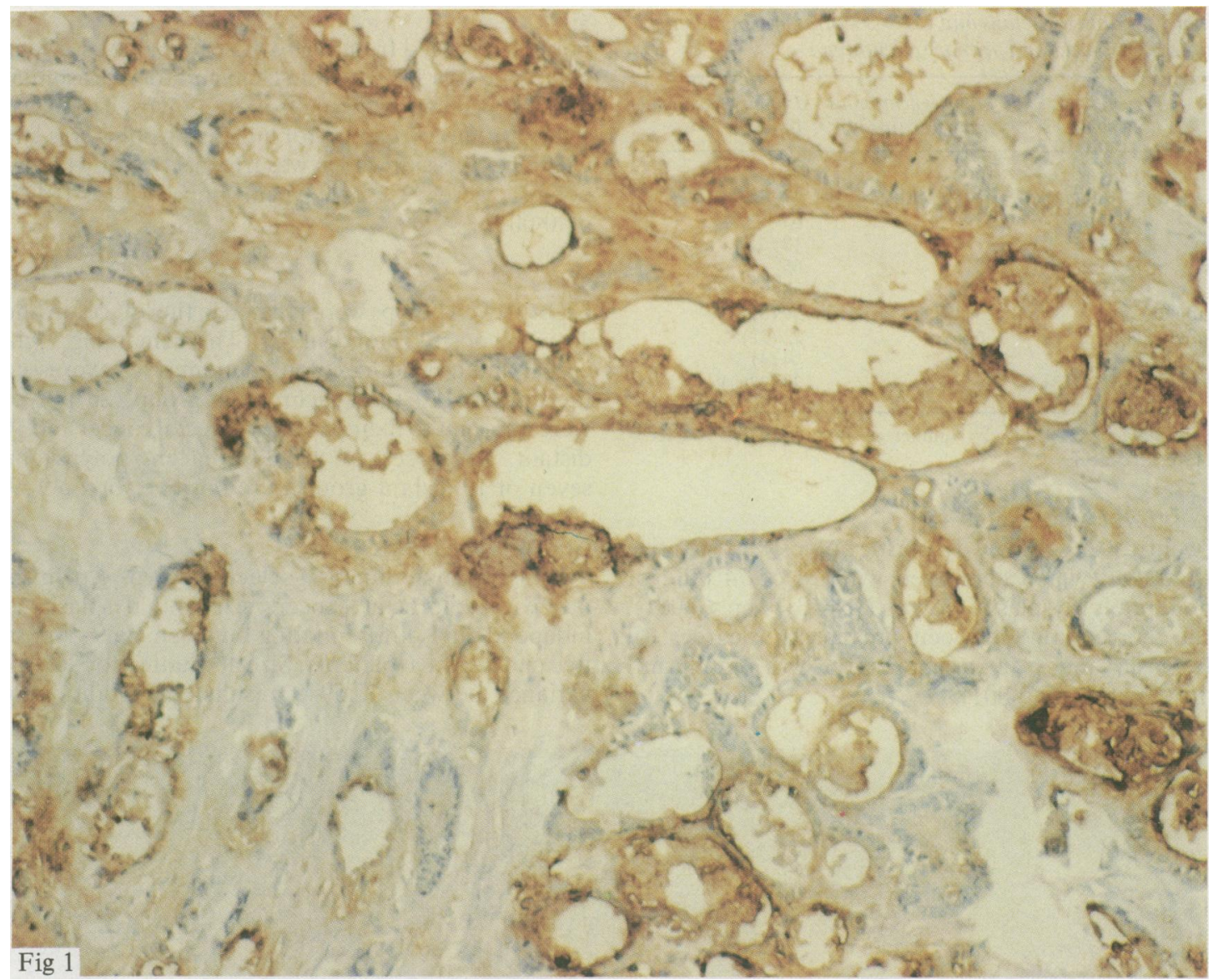

Fig. 1 Moderately differentiated adenocarcinoma showing Cal9-9 localtsation diffusely in the apical cells and glandular secretion.

of epithelial cells and in the intraglandular secretions (Fig. 1). Strong cytoplasmic staining was also seen in poorly differentiated colorectal cancers. Histologically normal, so called 'transitional' mucosa adjacent to colorectal cancer was focally positive in 12 of 42 cases.

\section{Adenomatous polyps}

Sixteen of the patients with colorectal cancer had 30 synchronous polyps while a further 36 patients presented with a total of $651^{\circ}$ adenomata over the 12 months. Patient details and histology of polyps are shown in Table 2. Eighty per cent of synchronous polyps expressed Cal9-9 compared with only $37 \%$ of primary polyps $\left(\chi^{2}=13.56, p<0.001\right)$. Cal9-9 positivity correlated strongly with synchronicity of polyps $(\mathrm{Tau}=0.4005, \mathrm{p}<0.001)$.

Overall 48 of 95 polyps $(51 \%)$ expressed the antigen. The expression was focal and less intense than in colorectal cancer and only one $4 \mathrm{~cm}$ dysplastic tubulovillous adenoma was Grade 3. Localisation was in the surface epithelium and varied from one high power field to another within the same polyp (Figs 2 and 3 ).

Four patients with a colorectal cancer negative for Cal9-9 had coexistant synchronous polyps that were positive for the antigen. The clinical features of these four cases are outlined in Table 3. Multiple polyps (two to 10) were present in 18 patients. Antigen expression was not uniform in these patients but was generally seen in the larger, dysplastic polyps.

\section{HISTOLOGICAL TYPING}

Tubular adenomas accounted for $65 \%$ of the series with the remainder having variable villous component (Table 4). Cal9-9 was expressed in $40 \%$ of tubular polyps and $70 \%$ of adenomas with villous component $\left(\chi^{2}=6 \cdot 305, p<0 \cdot 01\right)$. Correlation between Cal9-9 expression and villous component was strong $(\mathrm{Tau}=0 \cdot 279, \mathrm{p}<0 \cdot 003)$. 
Table 2 Clinical details and Cal9-9 expression in patients with synchronous and primary adenomata

\begin{tabular}{|c|c|c|c|}
\hline & & $\begin{array}{l}\text { Polyp synchronous } \\
\text { with } C R C(n=30)\end{array}$ & $\begin{array}{l}\text { Primary adenomata } \\
(n=65)\end{array}$ \\
\hline \multicolumn{2}{|l|}{ Patients (n) } & 16 & 36 \\
\hline \multirow[t]{2}{*}{ Age (yr): } & Range & $31-80$ & $42-82$ \\
\hline & Mean & $63 \cdot 9$ & $65 \cdot 1$ \\
\hline Sex: & $\mathbf{M}: \mathbf{F}$ & $11: 5$ & $18: 18$ \\
\hline \multirow[t]{2}{*}{ Site: } & Left & 22 & 65 \\
\hline & Right & 8 & 0 \\
\hline \multicolumn{2}{|l|}{ Tubular } & $23(17)$ & $39(8)$ \\
\hline \multicolumn{2}{|c|}{ Tubulovillous } & $6(6)$ & $22(12)$ \\
\hline \multicolumn{2}{|l|}{ Villous } & $1(1)$ & $4(4)$ \\
\hline \multicolumn{2}{|c|}{ Cal9-9 Positive (\%) } & $24 *(80)$ & $24(37 \%)$ \\
\hline
\end{tabular}

${ }^{*} \chi^{2}=13.56, p<0 \cdot 001 ;(\quad)=$ Number positive for Cal9-9, CRC $=$ colorectal cancer.

DYSPLASia (see Table 4)

Twenty of 21 severely dysplastic polyps were positive for Cal9-9 when compared with 28 of 74 mild or moderately dysplastic polyps $\left(\chi^{2}=23 \cdot 70, \mathrm{p}<0 \cdot 001\right)$. The correlation between increasing degrees of dysplasia and Cal9-9 expression was significant. $(\mathrm{Tau}=0 \cdot 438, \mathrm{p}<0 \cdot 001)$.
SIZE

Polyp size varied from 0.3 to $4.5 \mathrm{~cm}$ (Table 5). Mean polyp size was $1.28+/-0.96 \mathrm{~cm}$ and this was similar for both primary and synchronous polyps. There was a very strong correlation for increasing polyp size and Ca19-9 expression which was irrespective of whether polyps were $1^{\circ}$ or synchronous $(\mathrm{Tau}=0.475$, $\mathrm{p}<0 \cdot 001)$.

\section{SITE}

Eighty seven polyps were located in the left colon and 40 were positive for Cal9-9. The remaining eight caecal and ascending colon adenomas all expressed the antigen. In the synchronous group, 20 polyps were adjacent to their parent colorectal cancer and 10 distant. Seventeen of the 20 adjacent polyps and seven of 10 distant group were positive for Cal9-9.

\section{DISCRIMINATE ANALYSIS}

The discriminate function selected polyps synchronous with colorectal cancer, size and dysplasia as independently differentiating between Cal9-9 positive and negative patients. Size accounted for $26 \%$ of variance between Cal9-9 results, the addition of

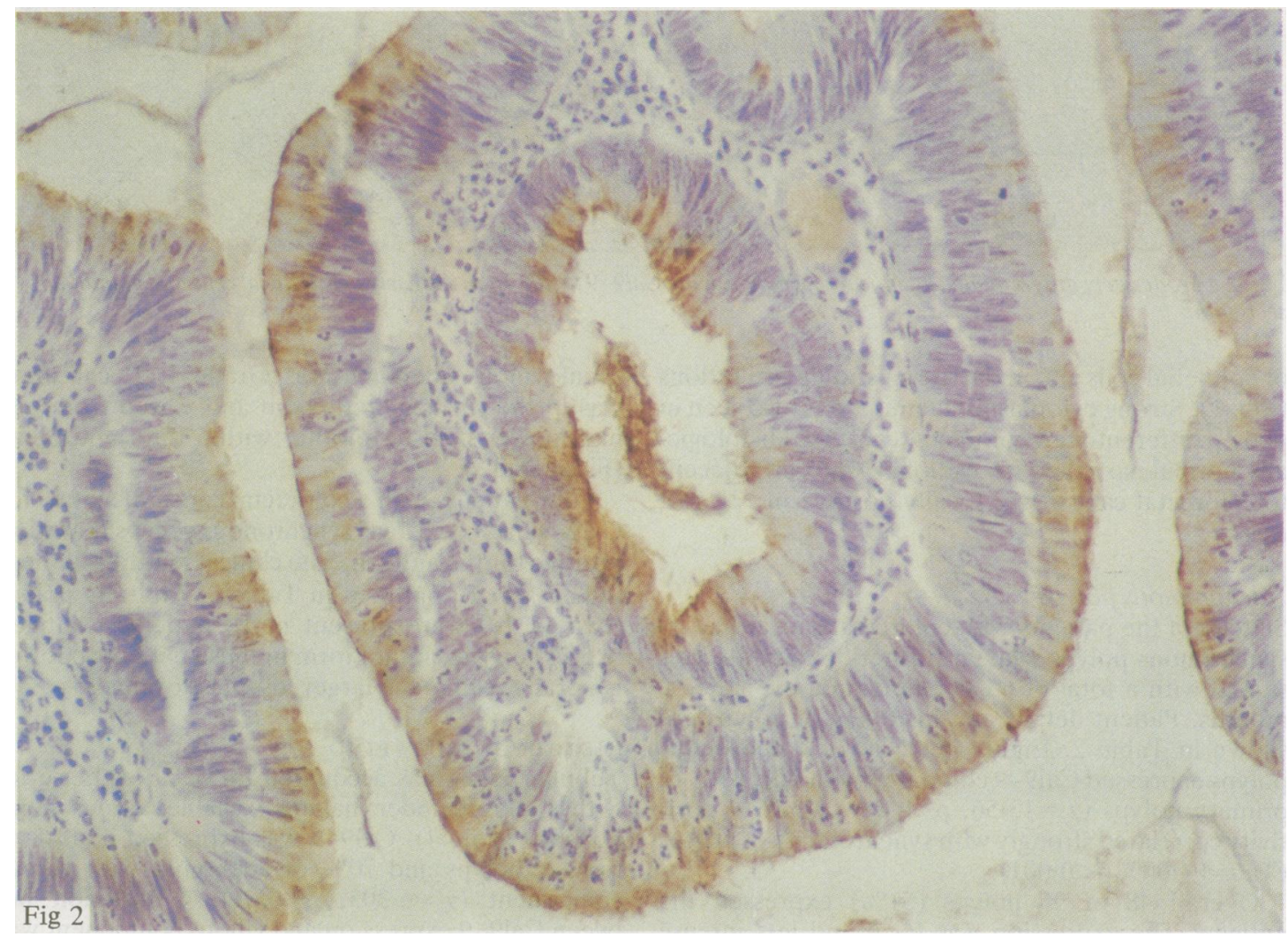

Fig. 2 Tubular adenoma, severely dysplastic demonstrating surface localisation of antigen. 


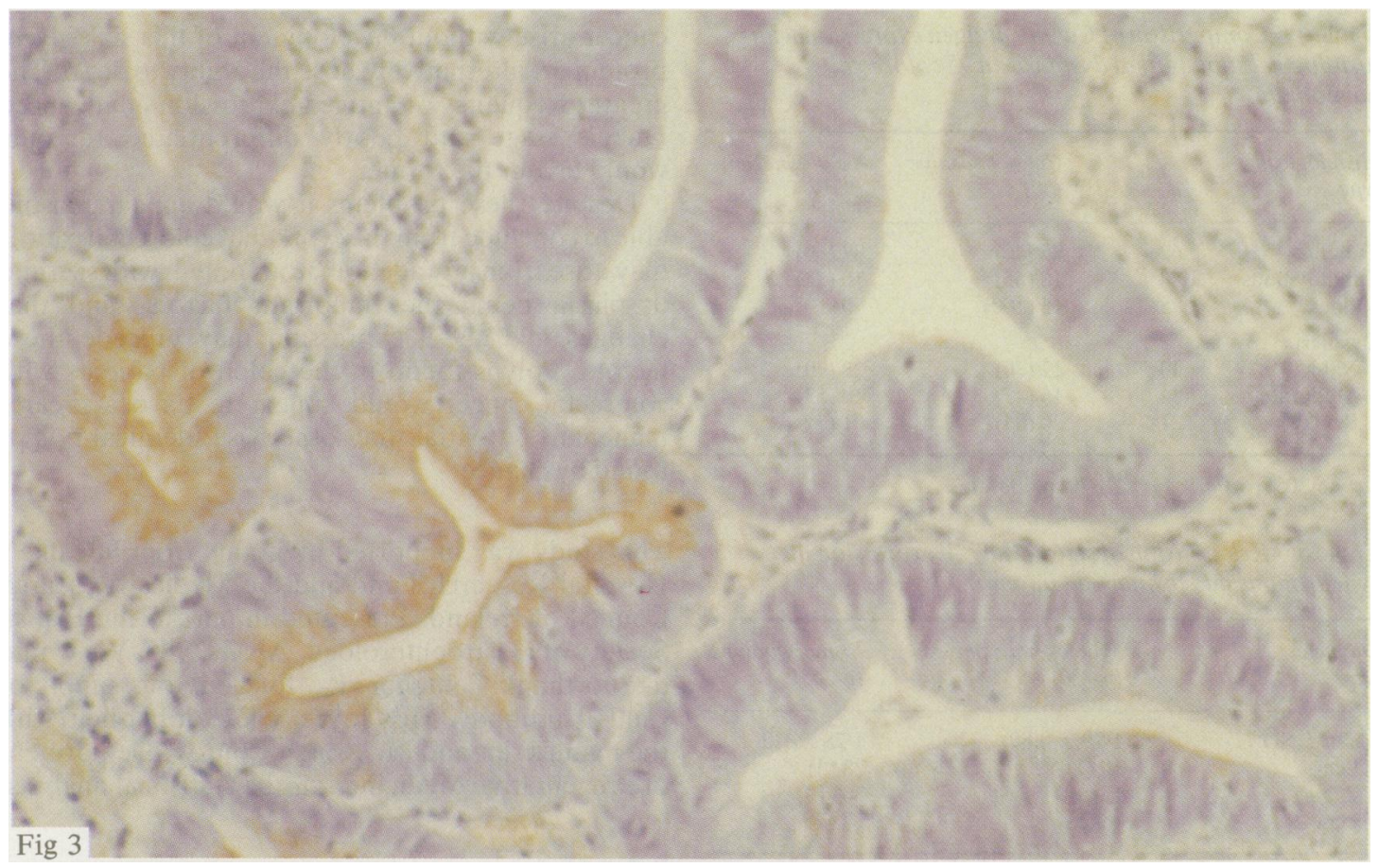

Fig. 3 Tubular adenoma showing focal grade 2 secretion of antigen maximal in areas of dysplasia.

polyp synchronicity increased the percentage of explained variance to $42 \%$ and the third factor, dysplasia increased this to $49 \%$ of Cal9-9 variation. The canonical correlation between the three factors and test result was $\mathbf{0} \cdot \mathbf{7 2}$. Overall, the three variables correctly classified $79 \%$ of positive and $89 \%$ of negative Cal9-9 results.

\section{Discussion}

The histological expression of the monoclonal antibody Cal9-9 in $60-75 \%$ of patients with colorectal cancer and its relative absence from normal colonic tissue $^{2012}$ marks it as a useful tool in the evaluation of putative premalignant states, such as the dysplasia seen in inflammatory bowel disease or, as in this study, the adenomatous polyp.

Overall $51 \%$ of polyps examined in this prospective manner displayed the antigen. Interestingly Cal9-9 correlated well with the accepted histological risk factors of size, severe dysplasia and villous component. ${ }^{27}$

Dysplasia and villous component of polyps have correlated well with other proposed markers of malignancy such as CEA and the lectin, peanut agglutinin. ${ }^{2324}$ The loss of villous component with discriminant analysis in our study, is probably accounted for by the fact that these polyps tended to be larger.

Division of our polyps into synchronous and primary showed a marked difference between the

Table 3 Clinical features of four patients with colorectal cancer negative for Cal9-9 but with positive synchronous adenomata

\begin{tabular}{|c|c|c|c|c|c|c|}
\hline \multirow[b]{2}{*}{ Case } & \multicolumn{3}{|c|}{ Carcinoma-negative for $\mathrm{Cal} 9-9$} & \multicolumn{3}{|c|}{ Synchronous adenoma - positive for Cal9-9 } \\
\hline & Site & Duke's stage & Differentiation & Histological type & Dysplasia & Size $(\mathrm{cm})$ \\
\hline 1 & Rectal & D & Undifferentiated & Tubular & Moderate & $1 \cdot 0$ \\
\hline 2 & Sigmoid & $\mathrm{C}$ & Moderate & $\begin{array}{l}\text { (1) Tubulovillous } \\
\text { (2) Tubulovillous }\end{array}$ & $\begin{array}{l}\text { Severe } \\
\text { Mild }\end{array}$ & $\begin{array}{l}1 \cdot 5 \\
3 \cdot 0\end{array}$ \\
\hline 3 & Sigmoid & B & Moderate & Tubular & Severe & $1 \cdot 0$ \\
\hline 4 & Sigmoid & B & Moderate & Tubulovillous & Severe & $4 \cdot 0$ \\
\hline
\end{tabular}


Table 4 Comparison of Cal9-9 antigen expression with histological subtype and dysplasia in 95 colorectal adenomata

\begin{tabular}{lcll}
\hline $\begin{array}{l}\text { Histological } \\
\text { type }\end{array}$ & $n$ & $\begin{array}{l}\text { Cal9-9 positive } \\
(\%)\end{array}$ & $\begin{array}{l}\text { Cal9-9 negative } \\
(\%)\end{array}$ \\
\hline $\begin{array}{l}\text { Tubular } \\
\text { Tubulovillous }\end{array}$ & 62 & $25(40)$ & $37(60)$ \\
Villous & 5 & $18(65)$ & $10(35)$ \\
Dysplasia & $5(100)$ & 0 \\
$\quad$ Mild & 40 & $12(30)$ & $28(70)$ \\
$\quad$ Moderate & 34 & $16(47)$ & $18(53)$ \\
$\quad$ Severe & $21 \dagger$ & $20(95)$ & $1(5)$ \\
\hline
\end{tabular}

${ }^{*} \chi^{2}=6 \cdot 305, \mathrm{p}<0 \cdot 01 ;+\chi^{2}=23 \cdot 70, \mathrm{p}<0 \cdot 001$.

Table 5 Relationship of size to Cal9-9 expression in synchronous and primary adenoma

\begin{tabular}{lll}
\hline $\begin{array}{l}\text { Diameter } \\
(\mathrm{cm})\end{array}$ & $\begin{array}{l}\text { Synchronous polyps } \\
(n=30)\end{array}$ & $\begin{array}{l}\text { Primary polyps } \\
(n=65)\end{array}$ \\
\hline Mean \pm SD & $1 \cdot 29 \pm 0 \cdot 89$ & $1 \cdot 28 \pm 1 \cdot 0$ \\
$<1 \mathrm{~cm}$ & $10(7)$ & $28(3)$ \\
$1-2 \mathrm{~cm}$ & $15(12)$ & $30(14)$ \\
$>2 \mathrm{~cm}^{*}$ & $5(5)$ & $7(7)$ \\
\hline
\end{tabular}

( ) =number positive for Cal9-9; ${ }^{*} \tau=0.475, \mathrm{p}<0 \cdot 001$.

two groups. This difference in Cal9-9 is not explained by clinical features since size, dysplasia and histological typing was similar in both groups. A spillover effect from the parent colorectal cancer is also unlikely, as both adjacent and distant polyps expressed Cal9-9. The independence of the synchronous polyp from the parent colorectal cancer is further highlighted by the presence of positive polyps in four patients with negative parent colorectal cancers.

The almost equal incidence of antigen expression in colorectal cancer and synchronous polyps suggests a possible field change in the tumour bearing colon. As only $28 \%$ of colorectal cancer had antigen in the 'transitional' mucosa, perhaps a certain mass of proliferating cells must be produced before Cal9-9 is expressed in sufficient quantity to be detected by an immunohistochemical technique.

The presence of $\mathrm{Cal9-9}$ in the 'transitional' mucosa and in a minority of the smaller, mildly dysplastic polyps is of particular interest. This would suggest that although structure and function of cells are closely related that functional changes, such as in mucin production, may precede morphological changes. Screening for changes in sialoglycoprotein secretion may be of value in predicting patients at high risk for colorectal cancer.

The failure of $25 \%$ of the colorectal cancer in this series to express Cal9-9 suggests that some colorectal cancer arise without development of this sialoglycoprotein or, alternatively, lose the ability to do so. The greater frequency of antigen expression in advanced Duke's stage and poorly differentiated tumours would favour the former.

Despite these problems it would appear reasonable to conclude from this work that colorectal cancer may arise from any adenomatous polyp, with size and dysplasia being the important factors, and that changes in Cal9-9 expression may precede these factors. Polyps found in the colon of patients with colorectal cancer would appear to have a greater malignant potential than otherwise identical polyps found by chance.

This study was supported by grants from St Luke's Hospital Research Fund and the Medical Research Council of Ireland. Presented in part to the British Society of Gastroenterology, April, 1985. We would like to thank Centocor, Pa. for generous supply of Cal9-9 antibody, Miss Joyce Foley for her help with the manuscript and Mr Ronan Conroy, Department of Preventative Medicine, for the statistical analysis.

\section{References}

1 Harkin K, MacMahon B, Doyle JS, Kinsella IA. Mortality analysis of colorectal carcinoma in Ireland; time trends and an international comparison. Ir J Med Sci $1985 ; 154: 343-7$.

2 Muto T, Bussey HJR, Morson BC. The evolution of cancer of the colon and rectum. Cancer 1975; 36: 2251-70.

3 Enterline HT, Arvan DA. Chromosome constitution of adenoma and adenocarcinoma of the colon. Cancer 1967; 20: 1746-59.

4 Grinnell RS, Lane N. Benign and malignant adenomatous polyps and papillary adenomas of the colon and rectum. An analysis of 1856 tumours in 1335 patients. Surgery 1958; 106: 519-38.

5 Lane $\mathrm{N}$. The precursor tissue of ordinary large bowel cancer. Cancer Res 1976; 36: 2669-72.

6 Hill MJ, Morson BC, Bussey HJR. Aetiology of adenoma-carcinoma sequence in large bowel. Lancet 1978; 1: 245-7.

7 Konishi F, Morson BC. Pathology of colorectal adenomas: a colonoscopic survey. J Clin Pathol 1982; 35: $830-41$.

8 Koprowski H, Herlyn M, Steplewski Z, Sears HF. Specific antigen in serum of patients with colon carcinoma. Science 1981; 212: 53-5.

9 Herlyn M, Steplewski Z, Herlyn D, Koprowski H. Colorectal carcinoma-specific antigen: Detection by means of monoclonal antibodies. Proc Natl Acad Sci USA 1979; 76: 1438-42.

10 Steplewski Z, Chang TH, Herlyn M, Koprowski H. Release of monoclonal antibody-defined antigens by human colorectal carcinoma and melanoma cells. Cancer Res 1981; 41: 2723-7. 
11 Herlyn M, Sears HF, Steplewski Z, Koprowski H. Monoclonal antibody detection of a circulating tumourassociated antigen. Presence of antigen in sera of patients with colorectal, gastric and pancreatic carcinoma. J Clin Immunol 1982; 2: 135-40.

12 Atkinson B, Ernst C, Herlyn M et al. Gastrointestinal cancer-associated antigen in immunoperoxidase assay. Cancer Res 1982; 42: 4280-3.

13 Arends JW, Wiggers T, Schutte B et al. Monoclonal antibody (1116 NS 19-9) defined monosialoganlioside (GICA) in colorectal carcinoma in relation to stage, histopathology and DNA flow cytometry. Int J Cancer 1983; 32: 289-93.

14 Kuusela P, Jalanko H, Roberts $P$ et al. Comparison of Cal9-9 and carcinomebryonic antigen (CEA) levels in the serum of patients with colorectal disease. $\mathrm{Br} J$ Cancer 1984; 49: 135-9.

15 Jalanko H, Kuusela P, Roberts $P$ et al. Comparison of a new tumour marker, Cal9-9, with fetoprotein and carcinoembryonic antigen in patients with upper gastrointestinal diseases. J Clin Pathol 1984; 27: 218-22.

16 Magnani JL, Brockhaus M, Smith DF et al . A monosialoganglioside is a monoclonal antibody defined antigen of colon carcinoma. Science 1981; 212: 55-6.

17 Hanisch F, Uhlenbruck G, Dienst C. Structure of tumour-associated carbohydrate antigen Cal9-9 on human seminal plasma glycoproteins from healthy donors. Eur J Biochem 1984; 144: 467-74.

18 Raux H, Labbe F, Fondaneche MC, Koprowski H, Burtin P. A study of gastrointestinal cancer-associated antigen (GICA) in human fetal organs. Int $J$ Cancer 1983; 32: 315-9.

19 Arends JW, Verstijnen K, Bosman FT, Hilgers J, Steplewski Z. The distribution of 1116 NS 19-9 monoclonal antibody defined monosialoganglioside in normal and cancerous human tissues. Hybridoma 1983; 2: 81-91.

20 Long A, Tobin B, O'Donoghue DP. Ca 19-9 antibody in colorectal carcinoma and colonic adenomata. Ir J Med Sci 1985; 154: 46.

21 Turnbull RB, Kyle K, Watson FR, Spratt J. Cancer of the colon: influence of the no touch isolation technique on survival rates. Ann Surg 1967; 168: 420-7.

22 Morson BC, Sobin LH, eds. Histological typing of intestinal tumours. In: International histological classification of tumours. Vol. 15. Geneva, WHO: 1976

23 Isaacson P, LeVann HP. The demonstration of carcinoembryonic antigen in colorectal carcinoma and colonic polyps using an immunoperoxidase technique. Cancer 1976; 38: 1348-56.

24 Boland RC, Montgomery CK, Kim YS. A cancerassociated mucin alteration in benign colonic polyps. Gastroenterology 1982; 82: 664-72. 